\title{
Elaborating the sensory and cognitive- affective aspects of information experience
}

\author{
Reijo Savolainen
}

Tampere University, Finland

Faculty of Information Technology and Communication Sciences

Kanslerinrinne 1

FIN-33010 Tampere University

Finland

e-mail: Reijo.Savolainen@tuni.fi

\begin{abstract}
Drawing on pragmatist ideas proposed by John Dewey, the study elaborates the picture of information experience (IE) by examining how researchers have characterized the ways in which people receive, acquire and interpret sensory and cognitive-affective information. To this end, a conceptual analysis was conducted by concentrating on 43 studies pertinent to the topic. The findings indicate that so far, the construct of IE has remained quite vague. This is mainly due to that experience - the fundamental constituent of IE - has not been sufficiently reflected in the context of informational phenomena. IE studies have mainly contributed to information behaviour research by describing how people receive and acquire sensory information, while the picture of experiencing cognitive-affective information has remained quite vague. There are also gaps in studies examining how sensory and cognitive-affective information are interpreted as an integral part of IE. The study also identifies topics of further research dealing with the elaboration of the construct of IE.
\end{abstract}

Keywords

Human experience, Information behaviour, Information experience 


\section{Introduction}

Information experience (IE) is a relatively new construct in library and information science (LIS). IE has generally been defined as the ways in which people "engage with information in real-world contexts" (Bruce et al., 2014: 4). IE research advocates a first-person perspective on the informational phenomena by giving preference to individuals describing how they become informed (Gorichanaz, 2019). With this approach, IE research takes the analysis of human experience as a point of departure. The significance of the study of experience has been recognized long ago in diverse domains such as education science and anthropology. Geertz (1986: 374) argued that without the scrutiny of human experience, cultural analyses remain at an abstract level, "floating several feet above their human ground". This notion is also relevant for LIS. Without devoting attention to how people subjectively experience information seeking, use and sharing, the findings of information behaviour research may remain overly abstract.

So far, the issues of IE have mainly been examined in the context of information literacy (IL). Interest in the issues of IE commenced at the Queensland University of Technology, Australia in the early 1990s, with studies examining doctoral students' experiences of literature reviews (Bruce, 1994). With her PhD thesis, Christine Bruce (1997) initiated a research program exploring how people experience using information to learn. Later on, the research program was expanded to deal with people's IEs more generally (Bruce et al., 2014a). To examine this topic, IE studies have preferred qualitative methods, particularly phenomenography (Yates, Partridge and Bruce, 2012). Recently, there is a growing research interest in related issues such as document experience and document phenomenology (Gorichanaz and Latham, 2016; Latham, 2014). Despite these developments, many of the IE studies are exploratory in nature and they are plagued by the lack of conceptual clarity.

The present study was inspired by my sceptic reflections upon the meaningfulness of the construct of IE. Is it really possible for an individual to "experience" information because the object of experience is an abstract and intangible entity? What exactly happens when an individual "experiences" piece of information: what is meant by "experiencing" or "experience" in this particular context? My further orientation to these issues was greatly helped by the reading of the book Technology as Experience, written by of McCarthy and Wright (2004). Drawing on the ideas of John Dewey - a leading proponent of pragmatist philosophy - they demonstrated that approaching the use of information technology in terms of human experience opens a novel perspective on the informational phenomena. According to McCarthy and Wright (2004: 17), pragmatist philosophy is particularly clarifying with respect to human experience because pragmatism conceptualizes knowing, doing, feeling, and making sense as inseparable elements of felt life. It is evident that due to its generic nature, the pragmatist perspective is also relevant for the examination of IE as a particular type of human experience.

Following this idea, the main goal of the present study is to elaborate the conceptual picture of IE by concentrating on the aspects of perceiving, knowing and feeling constitutive of human experience. To achieve this, this study develops a framework for conceptualizing 
information experience by drawing on John Dewey's concept of human experience and then examines the extent to which the components of the framework are constructed in existing studies. In so doing, it aims to reveal gaps and areas for future research. With this approach, the study sheds additional light on the ways in which IE is constituted as a way of receiving, acquiring and interpreting sensory (corporeal, embodied), cognitive and affective information.

The rest of the article is structured as follows. First, to provide background, approaches to the concepts of experience and IE are reviewed, followed by the explication of research questions and methodology. The main part of the article consists of the communication of the findings elaborating the characteristics of sensory and cognitive-affective aspects of IE. The last sections discuss the findings and draw conclusions of their significance.

\section{Background}

\section{What is meant by human experience?}

As an all-pervasive quality of human existence, experience is difficult to define in detail. This is because experience manifests itself as a multi-layered phenomenon: individuals make sense of experience through sensory, cognitive, personal interpretive, social and cultural layers (Fox, 2008). The etymology of the English experience dates back to the 14th century, stemming from Latin experientia which means "testing of possibilities, participation in events, skill gained by practice" (Merriam-Webster, 2019). In German language, the concept of experience has been split into two words. Erlebnis refers to a person's experience as lived through: the undergoing of some noticeable event, as apprehended through the senses or mind, affecting him or her here and now. Erfahrung describes the practical wisdom gained over time, i.e., the accumulation of knowledge or skill that results from direct participation in events or activities (von Glasersfeld and Ackermann, 2011: 194). Of the above aspects, Erlebnis is more pertinent to the present study because it characterizes human experience as a dynamic phenomenon: something that a person is living through.

Human experience is a perennial topic that has been examined in diverse terms such as learning experience (Roth and Jornet, 2014) and consumer experience (Roederer, 2012). The issues of experience have also been analysed by distinguished philosophers such as Hume, Kant, Dilthey, Husserl and Dewey. Hume and Kant primarily approached human experience in terms of Erfahrung by concentrating on the criteria by which it is possible to acquire knowledge (Lash, 2006). Dilthey conceptualized experience as Erlebnis - a "living through of experience" - as a sequence of events (erleben) and the retrospective attribution of meaning tied to the structuring of "experience" as a particular coherent unit or form (Erlebnis) (Throop, 2003: 223). The nature of Erlebnis has also been elaborated by phenomenologists such as Husserl. Phenomenology examines the structure of various types of experience ranging from perception, thought, memory, imagination, emotion, desire, and volition to bodily awareness and embodied action. The structure of various forms of experience typically involves what Husserl called intentionality, that is, the 
directedness of experience toward things in the world. Therefore, consciousness is always consciousness of or about something (Smith, 2013).

However, as the structure of experience is not central to the present study, the characterization of human experience primarily draws on the pragmatist ideas proposed by Dewey. Pragmatist philosophy is particularly clarifying while approaching experience from the perspective of Erlebnis, more specifically, from the viewpoint of felt life and the emotional and sensual character of action and interaction (McCarthy and Wright, 2004: 17-18). For pragmatists such as Dewey, experience is more inclusive than knowledge (Erfahrung) because experience tries to encapsulate a person's full relationship - sensory, emotional, and intellectual - with his or her physical and social environment (McCarthy and Wright, 2004: 54). According to Dewey (1929: 10-11), experience includes "what men do and suffer, what they strive for, love, believe and endure, and also how men act and are acted upon, the ways in which they do and suffer, desire and enjoy, see, believe". Unifying emotion is necessary for the formation of an experience. Whatever the particular emotion, joy or fear, the emotional tone holds an experience together. Without this emotional engagement, any experience would lack unity and would fail to be an experience.

Drawing on the above ideas, McCarthy and Wright (2004) identified diverse threads or aspects of experience relevant to the analysis of technology as experience in particular. Due to their generic nature, two of these threads are also relevant for the analysis of IE. First, the sensual thread deals with the concrete, palpable, and visceral character of experience (McCarthy and Wright, 2004: 80-81). It draws attention to things being grasped pre-reflectively as the immediate sense of a situation in which the wonder of the material world is made actual for us in the quality of experience. To illustrate the sensual aspect, Dewey described a mechanic who has a strong sense of an engine and of the interaction between his tools and the engine. He can hear the slightest problem with an engine, and he can feel the rhythm of an engine running smoothly or a spanner turned a fraction tight. Second, there is the emotional thread (McCarthy and Wright, 2004: 83-84). Emotions qualify experiences by giving them a positive or negative tone. Emotions also affect the ways in which people engage themselves in diverse situations and the extent to which they are concerned with the movement of events toward an outcome that is desired or disliked. From the Deweyan perspective, human experience is constituted by two processes: receiving or acquiring sensory and emotion-based information of the life-world and interpreting it in order to make the information meaningful.

\section{Characterizations of information experience}

Researchers examining the phenomena of information experience have seldom reflected the nature of the second part of the compound word, that is, experience; it tends to be taken as a black-boxed or self-explanatory concept. Unreflective approaches have often resulted in a vague understanding of the concept of IE, thus reducing its discriminatory power. For example, researchers may claim that they have explored information-seeking experiences among a group of people (e.g., Emanuel et al., 2018). However, a closer analysis reveals that the findings describe the ways in which the study participants actually sought access to information sources; the analysis of how they subjectively "felt" the events of seeking 
information is lacking. The characterizations of IE have also been affected by the use of varying terminology. In addition to "information experience", researchers have employed related terms such as "experiencing information" (Godbold, 2014) and "informationseeking experience" (Clark, 2014).

Thus far, perhaps the most influential contribution to IE research is the monograph Information Experience: Approaches to Theory and Practice, edited by Christine Bruce and her associates. The book was published in 2014, and it contains altogether 19 papers presenting a range of perspectives on IE. The editors of the book defined IE as "the way in which people experience or derive meaning from the way in which they engage with information and their lived worlds as they go about their daily life and work" (Bruce et al., 2014b: 6). Though illuminating as an introductory characterization of IE, the above definition is not without problems because the authors did not explicate the meaning of the key constituent of IE, that is, "engagement with information". Nevertheless, Bruce and associates (2014b: 6) believed that the construct of IE will open a new research perspective because it is a "distinct and integrative concept". This is because IE emphasizes the importance of holistic approach to people's informed existences, considering people and what informs them, within their wider environments, in a manner which considers people and their world as inseparable. Thereby, IE would "integrate people's thoughts, feelings, senses, and actions; as well as their social and cultural influences" (Bruce et al., 2014a: 316). Interestingly, the above characterization comes close to Dewey's holistic ideas about human experience, even though the authors did not refer to Dewey or other pragmatist philosophers.

Other researchers have characterized IE somewhat differently. Heinström (2014: 275) adopted a psychological perspective by suggesting that IE deals with an "individual's inner experience when he or she is interacting with information". IE may occur in anticipation of an information interaction, during it, or as a consequence of it. The psychological characterization differs from the practice-theoretical perspective on IE advocated by Lloyd (2014). She acknowledged the difficulty of defining IE by reminding that "while the concept of information is tricky, the concept of experience is even trickier, because experience cannot be understood in its own right, but requires reference against the coconstructions that constitute a particular practice or performance of a practice" (Lloyd, 2014: 87). Drawing on Fox (2008: 41), experience was generally defined as a "complex interaction between body, sensory input, and neurological processing - a relationship with the world as humans encounter, interpret and shape messages". However, Lloyd reminded that IE cannot be meaningfully defined as a stand-alone construct, independent on its particular context. Conversely, IE must be "referenced against the information landscapes that people engage with and recognise the meaning that is attributed to them through social or physical experience of information" (Lloyd, 2014: 87).

\section{Conceptual framework and research questions}

The above review indicated that experience is a pervasive and multi-faceted phenomenon of human existence which defies a generally accepted definition. It also appeared that the construct of IE can be characterized in multiple ways. Common to these characterizations 
is the assumption that IE is a fundamental aspect of human experience because our ways to make sense of the world is based on the reception and interpretation of information. However, this does not mean that human experience and IE would be identical. In addition to informational aspects, human experience may incorporate aesthetic or other aspects that are not primarily "informational" in nature. Notwithstanding, the present study focuses on the informational aspect of human experience referred to as information experience.

Information experience is a compound noun consisting of two components, i.e., information and experience. The former component is a notoriously vague concept. Bates (2017) provides an authoritative overview of the multiple meanings of information. First, information may be conceived of as a process of being informed, similar to Buckland's (1991) view on information-as-a-process. Second, information can be defined as a claim about the world, a proposition. Information denotes an abstract, meaningful representation of determinations which have been made of objects. Third, social definitions emphasise that information is a socially constructed human artefact within social situations. Fourth, structural definitions propose that the structuring and organizing of information contains its own information, and is therefore likewise informative. Bates's (2017: 2057) own definition of information draws on the structural viewpoint: 'information is the pattern of organization of matter and energy'. Information is not identical to the physical material that composes it; rather information is the pattern of organization of that material, not the material itself.

The multiplicity of the above viewpoints suggests that the understanding of the core concept of information remains a highly contested area. Case and Given (2016: 76-77) concluded that defining information in an absolute sense is not necessary for the study of information behaviour. It is more productive to treat information as a primitive term, without needing a full explication. From this perspective, information is a phenomenon that can be recognised when we see it in its various forms or modes, for example, as a message, proposition, or a socially constructed human artefact. The present study adopts the broad approach proposed by Case and Given. This view is preferred, because understanding information as a primitive concept does not unnecessarily restrict the analysis of the ways in which this entity, however vague, is experienced. To this end, the present study brackets the particular meanings of the concept of information identified by Bates (2017) while scrutinising the nature of IE.

Drawing on Dewey's pragmatist ideas reviewed above, experience is conceptualized as dynamic phenomenon constituted by two processes: (i) receiving and/or acquiring information, and (ii) interpreting information. The first component of the construct of IE, that is, information - that what is being experienced - is approached by differentiating two types of information. Sensory information is indicative of the concrete, palpable, and visceral character of experience (McCarthy \& Wright, 2004, 80-81). As explained below, another type is cognitive-affective information that is indicative of the emotional thread conceptualized by McCarthy and Wright (2004: 83-84).

On this basis, the processes of receiving, acquiring and interpreting sensory information will be referred to as experiencing sensory information. IEs of this type deal with how 
individuals (subjectively) receive and acquire information through human senses: sight, hearing, touch, smell and taste. Researchers have used diverse terms while referring to information of this type: corporeal information; physical information (Lloyd, 2009), kinaesthetic information; tactile information (Lupton, 2014), and embodied information (Cox, 2018). For clarity, the present study prefers the term sensory information while referring to information received through human senses from physical (tangible) objects such one's own body and things of external world. Sensory information has a material (objective) basis in two meanings. First, information of this type is derived from physical objects. Second, stimuli received from material objects (by sensory receptors) are physical in nature because ultimately, such stimuli are based on changes occurring in the chemical structure of an organism's internal or external environment. However, the present study does not examine the material (objective) characteristics of sensory information. The focus is placed on the subjective aspect of information of this type, that is, the ways in which an individual subjectively interprets the physical stimuli received through senses. Furthermore, for clarity, the expression of "experiencing sensory information" is preferred over "sensory information experience" because the former captures better the dynamic nature of IE.

As noted above, Dewey also characterized the "emotional" aspect of experience. In the present study, however, a broader term, that is, affective is preferred because it incorporates both emotions and feelings (Davidson et al., 2003: xiii). Emotion refers to a relatively brief episode of coordinated brain, autonomic and behavioural changes that facilitate a response to an external or internal event of significance for the organism. Feeling is a subjective representation of an emotion; feelings can reflect any or all of the components that constitute emotion such as fear or hope. On this basis, affective information can be understood as a stimulus event that serves as a cue to the (dis)likability or (un)approachability of the event (Niedenthal, 1990). Said otherwise, affective information refers to positive or negative impressions from feelings. Impressions of fear before a medical examination exemplifies a stimulus event of experiencing affective information.

As the affective factors of experience tend to co-exist with cognitive ones, the conceptual framework was substantiated by incorporating the aspect of cognitive information. In general, the term cognition describes the intellectual or perceptual processes occurring within the mind when a person analyses and interprets both the world around herself and her own thoughts and actions (Petri and Govern, 2004: 248). In general, cognitive information deals with stimulus events related to attention, memory, and activities such as planning, reasoning, learning, analyzing, concluding, evaluating, problem solving and decision making (Sternberg, 2009). For example, recalling a past event about reading a textbook exemplifies a case in which a person experiences memory-based cognitive information. The present study departs from the assumption that affect and cognition can only analytically be defined as separate aspects of human experience. Since the 1980s, a growing number of researchers has taken the position that cognition and emotion are seamlessly conjoined or fused in nature (Lazarus, 1999: 10-11; Pessoa, 2008). On this basis, the present study prefers the expression of experiencing cognitive-affective information. 
In sum, the above framework conceptualizes IE as a process in which individuals subjectively receive, acquire and interpret sensory and cognitive-affective information. To examine the nature of IE in greater depth, the present study seeks answers to the following questions:

RQ1. How have researchers characterized the processes of experiencing sensory information?

RQ2. How have they characterized the processes of experiencing cognitive-affective information?

RQ3. What are strengths and weaknesses of such characterizations; what kind of implications do they have for IE research?

To strengthen the focus of the study, a few limitations appeared to be necessary. First, investigations concentrating on the issues of document experience or museum experience were excluded (for these studies, see Gorichanaz and Latham, 2016; Latham, 2014). Second, no attempts were made to analyse the ways in which the construct of information experience is approached in particular domains such as design research (Burmeister, Mangold and Tille, 2013) or the design of immersive information experiences in libraries and museums (Mitchell, 2013). It is evident that these topics would require a separate study.

\section{Methodology}

To answer the above questions, a conceptual analysis was conducted by focusing on pertinent IE investigations characterizing how people experience sensory and cognitiveaffective information. The research material was identified by searching seven major databases: EBSCO Academic Search Premier, ERIC, Google Scholar, Library and Information Science Abstracts, ScienceDirect, Scopus, and SpringerLink. The search terms included, for example, information experience, information information-seeking experience and experiencing sensory information. The searches resulted in the identification of 66 potentially relevant investigations published within the period of 19942019. The preliminary analysis revealed that many of these investigations are descriptive in nature, with no attempts to explicate the meaning of the concept of IE. After having excluded investigations of this kind, altogether 43 pertinent studies were included in the final sample. These studies were selected by two criteria. First, these investigations reflected the conceptual nature of IE by proposing definitions of information experience or reflecting how it is related to human experience. Second, investigations included in the sample offered relevant empirical examples of how sensory and cognitive-affective information is acquired and interpreted among diverse groups of people. Studies of this kind examine how people receive and seek information through human senses such as sight, hearing and touch, or recall information from memory and then interpret information thus acquired in order to make it meaningful. The investigations included in the sample are listed in Appendix 1.

The research material was scrutinized by means of conceptual analysis (Furner, 2004). This method treats the components of the study objects as classes of objects, events, properties, 
or relationships. More precisely, the analysis involves defining the meaning of a concept and its attributes by inductively identifying and specifying the contexts in which it is classified under the concept in question. To conduct the conceptual analysis, relevant text portions (paragraphs and sentences) characterizing the main object of the study, that is, information experience were identified. Such text portions were equipped with codes indicating the experiencing of sensory and cognitive-affective information. However, as the study is qualitative in nature, the frequency distribution of the codes was not calculated. Second, following Furner's (2004) terminology, the attributes of IE were identified from the coded material. Attributes specifying the experiencing of sensory information included, for example, feeling painful sensations (Godbold, 2014), while attributes describing cognitive-affective information entailed, for example, recalling a memory (Yates and Partridge, 2014). Third, the attributes thus identified were put into two categories according to the information component of IE: (i) experiencing sensory information and (ii) experiencing cognitive-affective information. The coding was rendered difficult in that the above types of information seldom appeared in a pure form. In cases in which the categories intertwined, the coding was based on the assessment of whether a text portion predominantly deals with experiencing sensory or cognitive-affective information. Fourth and most importantly, the conceptual analysis was conducted by scrutinizing the similarities and differences between diverse characterizations describing how sensory and cognitive-affective information is received, acquired and interpreted. The analysis was finalized by examining the strengths and weaknesses of such characterizations. To achieve this, the attention was devoted to the degree to which researchers had elaborated the characterizations of IE or left them unspecified.

\section{Findings}

\section{Experiencing sensory information}

The ways in which people receive or acquire sensory information is dependent on the human perception system. All perception involves signals that go through the nervous system, which in turn result from physical or chemical stimulation of the sensory system. Sensory information refers to signals and stimulations of this kind gathered by senses from the objects, as well as to the perception of the signal formed in the brain. From this perspective, body is the centre of human experience: what we can see, hear, touch, smell and taste (Mosunova, 2017). Even something as simple as body height impacts what is perceived (Lueg, 2014). Perception is also directly related to the ability to structure the flow of sensory information that falls on a person and is perceived by him or her as a multitude of various material signals and stimuli. From this perspective, experiencing sensory information is conceptualized as the reception of perceptual information transmitted by human senses (Mosunova, 2017: 176-176).

Experiencing sensory information does not purely occur at the level of neural processing but is also affected by cognitive factors which enable the interpretation of sensory information. For example, when a person feels acute pain in his chest for a few seconds, and then it goes away, he may interpret the pain as a symptom of angina pectoris. On the other hand, even simple physiological processes of perception require nonconscious 
screening processes (Fox, 2008: 42). To exemplify: the eye receives billions of bits of information of which the ocular nerve can only transmit a fraction. This suggests that selection and reduction of information is occurring even before its interpretation occurs at a conscious level. Therefore, an individual cannot simply "grasp" information from objective reality, because perception requires the joint action of memory, the ability to make inferences and achieve inference knowledge, attention, and imagination. In addition, sensory information received or acquired may incorporate elements giving rise to affective evaluation such as nice/awful or pleasant/unpleasant. Bates (2018: 243) offers a vivid example of the nature of experiencing sensory information that is selectively interpreted within the cognitive mind.

"When I stand on a cliff overlooking the San Francisco Bay and the Golden Gate Bridge, I "see" the bay, whatever that means. I do not see or feel the neurons firing that create that experience of the bay; I only experience myself as standing on the land experiencing the sight and feel of the bay, along with the scent of the saltwater and the brushing of my skin by the breeze".

Bates (2018: 243 emphasized that central to experiencing sensory information is that the observer approaches a site as a view of the site itself, with oneself at the centre of his or her view. The observer feels her weight on the ground and has a good three-dimensional picture of what surrounds her and where she is in relation to everything else. However, there is no conclusive theory explaining how human brain is able to take the sensory information that is impinging on our body and creating signals in nerves to the brain, and convert that input into a lived picture, an experienced embodiment, of the world around us (Bates, 2018: 243).

The ways in which people experience sensory information have been examined in diverse contexts such as social dancing hobby, self-care of kidney failure and grocery shopping. In these investigations, the main emphasis is placed on the description of how sensory information is received or acquired, while less attention has devoted to how sensory information is interpreted. For example, in social dancing, tactile and kinaesthetic information are received through touching the partner's body, as well as feeling the floor slippery or sticky (Lupton, 2014). As music played in the dance hall is a central source of sensory information, much of the formation of IE depends on hearing and listening to the ongoing piece of music. In Lupton's (2014) study, the dancers reported about hearing the music in particular ways that informed their response. Visual and spatial information come from observing the way other couples move around the floor. Another empirical example of events in which people receive and acquire sensory information as a part of IE is offered by Yates and Partridge (2014). They examined how people became aware of the threat of a potentially dangerous flood in their immediate external environment. Sensory information was not only received visually, but also through hearing the flooding river flow or smelling the stench from the flood.

Experiencing sensory information is often heightened in health-related contexts. Godbold (2014) explored renal patients received sensory information through bodily experience and 
experimentation during the self-care procedure. For example, painful sensations taught patients to recognise when he or she had pushed the needle in too far (Goldbold, 2014: 160). Painful sensations transmitted by neural connections are interpreted as immediately felt IEs. When a patient responded to pain by pulling a needle back slightly, the success of avoiding injury reinforced his or her understanding of the meaning of pain and led to her more confident attitude. Another example of the interpretation of sensory information is offered in Lloyd's (2009: 416) empirical study on IEs among ambulance officers. Over time, they developed "gut feelings", based on the performance of physical performance in diverse first-aid situations. Interpretation of such feelings occurred when they reflectively thought about past physical performance in the context of current situations while applying physical information acquired previously.

The features of experiencing sensory information have also been studied empirically by making use of auto-hermeneutics - a method enabling a systematic description of one's own personally lived experience. Gorichanaz (2017a; 2017c) tested the potential of this methodological approach in a study on ultrarunner's IEs. The questions examined in the study included, for example, how would the researcher himself experience information during the 100-mile race, and what sources would he turn to for information while running? The gathering of empirical data drew on systematic self-observation and memoing techniques. To achieve this, Gorichanaz (2017a: 5-6) scheduled alerts on his smartphone to prompt him every 45 min to conduct a self-interview focusing on the recent problems faced during running and the ways of dealing with them. Unsurprisingly, the study revealed that the chief source of information on the run was the researcher's own body, thus emphasizing the significance of acquiring sensory information as a part of the IE.

Ocepek's (2018) recent investigation on grocery store shoppers' IEs reflects the growing interest in the issues of embodied information, approached from the perspective of how the body "knows" through the human senses (Cox, Griffin and Hartel, 2018). Grocery shoppers relied on their sight, taste, touch, and smell while receiving and acquiring sensory information during the shopping process. Often, the interpretation of sensory information occurred almost simultaneously with the acquisition process. For example, seeing "ugly cuts of meat" resulted in the interpretation that this product should be avoided (Ocepek, 2018: 380). Tasting of food was important in making many of the purchase decisions. It also appeared that the participants made use of touch while selecting avocados, for example. Finally, smell was an important factor in making purchase decisions on food in particular.

The above studies suggest that the nature of IEs is deeply affected by the ways in which people receive and acquire situation-specific sensory information. It may originate from a variety of sources ranging from physical pain sensations of a renal patient to a pleasant touch by the dance partner. Bates (2018: 243) summarized well the essence of experiencing sensory information: "we feel that we are experiencing life directly, when in fact that experience is mediated by a multi-billion-cell nervous system that processes the original sensory input through many layers and conversions". However, experiencing sensory information is not merely a physiological process of receiving input by means of neurons. Experiencing sensory information only becomes meaningful when it is interpreted as 
something, possibly leading to an action such as quickly changing dance movements or making a purchasing decision.

\section{Experiencing cognitive-affective information}

Thus far, picture of how people experience cognitive-affective information has remained rudimentary. This may be due to the fact that IEs of this type tend to be interwoven with events in which people experience sensory information; this connection makes it difficult to identify the particular features of experiencing cognitive-affective information. To take an example of social dancing reviewed above, the reception and interpretation of kinaesthetic information may intertwine with receiving and interpreting cognitive-affective information dealing with the skilful dancing of the partner. Therefore, the basic dilemma deals with the extent to which it is possible to identify the experiences based on the reception, acquisition and interpretation of information dealing with stimulus events related to cognitive and affective factors. As noted above, cognitive information deals with stimulus events related to attention, memory, and activities such as planning, reasoning, learning, analyzing, concluding, evaluating, problem solving and decision making, while affective information serves as a cue to the (dis)likability or (un)approachability of the event. Thus, distinct from sensory information which originates from the immediate perception of a physical object, cognitive-affective information is received or acquired from intangible objects such as memories and feelings.

The nature of experiencing cognitive-affective information can be illuminated further by reviewing Godbold's (2014) investigation of the self-care procedures among renal patients. She differentiated between emotions and explanations as forms of IEs. For example, the procedure of pushing a needle into a vein may result in the experience of receiving affective information interpreted as fear. Affective information of this kind is triggered by the anticipation of a bodily sensation (pain) which is expected to be encountered during the short-lived episode of the procedure. Explanations (understandings) represent the reception and interpretation of memory-based cognitive information dealing with evaluation about what kind of procedures are less or more painful. Godbold's distinction between emotions and explanations is analytical in nature because experiencing affective information (fear) intertwine with experiencing cognitive information (evaluation of the painfulness of the recent self-care procedure). Experiencing cognitive-affective information may be even more negatively coloured in situations such as being diagnosed with cancer (Lambert, Loiselle and MacDonald, 2009). In such cases, IEs may be associated with avoiding rather than acquiring and interpreting (reflecting) cancer-related information; this is due to the human's inclination to avoid unpleasant and stressful outcomes.

Although experiencing cognitive and affective information tend to be tightly connected, such experiences may be emphasized differently, depending on the context of IE. Harlan's (2014) empirical study focusing on teen content creators exemplifies a case in which experiencing cognitive information occupies the primary role. Harlan examined how the study participants experienced information as artifact. For example, a website created by a teen is an information artifact in the sense of a concrete representation of both abstract knowledge and applied skills necessary to be able to create and share the website with 
others. Information is experienced as an artifact when a teen "sees" what he or she has created (Harlan, 2014: 112). Moreover, experiencing information as artifact provides immediate feedback about what a teen could create. Unfortunately, the above study left open the question about how to experience abstract knowledge, for example, an idea of the topic of a hobby-related website because such an idea is intangible. However, we may speculate that during the interpretation process, the teen evaluates how the preliminary idea of the website content could be realised in practice. It is also possible that the interpretation of cognitive information is intertwined with the appraisal of affective information because the reflection of the preliminary idea may give rise to positive or negative feelings.

The ways in which people experience cognitive-affective information have also been examined in phenomenographic studies focusing on information literacy. The goal of a phenomenographic study is to reveal the range of qualitatively different ways in which a group of people experience a phenomenon at a given moment in time (Yates and Partridge, 2014: 122). Phenomenographic investigations often concentrate on how people experience cognitive information because the focus is placed on the structure of awareness dealing with such information. Yates and Partridge's (2014) study offers a typical example of this approach. The investigation focused on people's ways to use information to learn during a natural disaster. The findings indicate that the experiencing of cognitive information occurred when a person consulted his or her own information resources available in memory. IE of this kind is initiated by recalling a past situation in which a piece of information about the risks of natural disaster appeared to be useful. Memory-based information thus retrieved is interpreted in the current situation. Interestingly, the event of experiencing sensory information is different in this regard because it emphasizes the centrality of immediate sensation transmitted by nerves to the brain. Experiencing cognitive information recalled from memory emphasizes the viewpoint re-interpreting information used in the past because the current situation may pose different requirements for the information seeker.

As reviewed above, experiencing cognitive-affective information is often a negatively coloured process in health-related contexts, due to fearful or worrisome anticipation of future events. The reception, acquisition and interpretation of positively coloured affective information occupies a primary role in contexts in which a person may obtain an optimal experience, often referred to as flow (Csikzentmihalyi, 1990). It is assumed that people are happiest when they are in a state of concentration or complete absorption with the activity at hand. Flow is a state in which people are so involved in an activity that nothing else seems to matter.

The phenomena of flow may occur in work-related as well as leisure contexts. For example, information seeking on social media can lead to alterations in an individual's sense of the duration of time - one of the characteristics of experiencing a state of flow (Afzal, 2018). Flow-related features have also been identified in leisure contexts such as amateur genealogy and music hobbies. Information seeking in itself may be experienced as thrilling and inherently pleasant because this activity is oriented by hedonic outcomes (Laplante and Downie, 2011). Pleasure is the direct result of their engagement with information and it is the reason why they continue their involvement with the leisure activity (Demasson, 
Partridge and Bruce, 2016). An empirical study of information-seeking experiences among amateur genealogists revealed that the potential for finding a bit of information generated feelings of excitement and eagerness to obtain further information (Fulton, 2009). Overall, the above examples suggest that particularly in flow-related contexts, IEs are primarily constituted by receiving or acquiring affective information which as a stimulus event serves as a cue to the likability of an action. Such stimulus events are interpreted as inherently pleasurable, thus motivating to lengthen the IE.

\section{Discussion}

Drawing on Dewey's holistic ideas of human experience as a constellation of sensory and emotional aspects, the present investigation contributed to information behaviour research by clarifying the conceptual nature of IE. Based on a conceptual analysis of pertinent IE studies, the present investigation elaborated the picture of the ways in which people experience sensory and cognitive-affective information. The main findings concerning these types of IE are summarized in Table 1. 
Table 1. Summary of the main findings.

\begin{tabular}{|c|c|c|}
\hline $\begin{array}{l}\text { Features } \\
\text { (attributes) } \\
\text { of IE }\end{array}$ & Examples of studies & $\begin{array}{l}\text { Main strengths (+) and } \\
\text { weaknesses (-) of studies } \\
\text { characterizing IEs }\end{array}$ \\
\hline $\begin{array}{l}\text { Experiencing } \\
\text { sensory } \\
\text { information } \\
\text { - receiving } \\
\text { and acquiring } \\
\text { perceptual } \\
\text { information } \\
\text { through } \\
\text { human senses } \\
\text { - interpreting } \\
\text { sensory } \\
\text { information }\end{array}$ & $\begin{array}{l}\text { - receiving and interpreting } \\
\text { kinaesthetic, auditory and visual } \\
\text { information in social dancing (Lupton, } \\
\text { 2014) } \\
\text { - renal patients acquiring and } \\
\text { interpreting tactile information during } \\
\text { self-care procedure } \\
\text { - ambulance officers receiving and } \\
\text { interpreting "gut feelings" (Lloyd, } \\
\text { 2009) } \\
\text {-multiple sensory-based IEs among } \\
\text { grocery shoppers (Ocepek, 2018) }\end{array}$ & $\begin{array}{l}+ \text { a variety of empirical } \\
\text { examples } \\
\text { illuminating how people } \\
\text { receive sensory information in } \\
\text { diverse contexts } \\
\text {-vague or lacking explications } \\
\text { of the concept of experience } \\
\text { - the characterizations of how } \\
\text { sensory information is } \\
\text { interpreted are descriptive and } \\
\text { quite general in nature }\end{array}$ \\
\hline $\begin{array}{l}\text { Experiencing } \\
\text { cognitive- } \\
\text { affective } \\
\text { information } \\
\text { - receiving } \\
\text { and acquiring } \\
\text { cognitive- } \\
\text { affective } \\
\text { information } \\
\text {-interpreting } \\
\text { cognitive- } \\
\text { affective } \\
\text { information }\end{array}$ & $\begin{array}{l}\text { - emotions and explanations as forms } \\
\text { of experiencing affective and } \\
\text { cognitive information (Godbold, } \\
\text { 2014) } \\
\text { - characterizing the acquisition and } \\
\text { interpretation of cognitive information } \\
\text { by approaching information as artifact } \\
\text { (Harlan, 2014) } \\
\text {-instances of experiencing cognitive } \\
\text { information about natural disaster by } \\
\text { recalling a memory (Yates and } \\
\text { Partridge, 2014) } \\
\text {-flow-related acquisition } \\
\text { interpretation of affective information } \\
\text { in the context of hobbies (Fulton, } \\
\text { 2009; Laplante and Downie, 2014) }\end{array}$ & $\begin{array}{l}+ \text { a few empirical examples } \\
\text { illuminating how people } \\
\text { receive and acquire cognitive } \\
\text { and affective information } \\
\text { - vague or lacking explications } \\
\text { of the concept of experience } \\
\text { - the characterizations of how } \\
\text { cognitive-affective } \\
\text { information is interpreted are } \\
\text { quite unspecific } \\
\text { - the paucity of broader } \\
\text { empirical evidence of the } \\
\text { reception and interpretation of } \\
\text { cognitive-affective } \\
\text { information }\end{array}$ \\
\hline
\end{tabular}

Research questions 1 and 2 dealt with the ways in which researchers have characterized the experiencing of sensory and cognitive-affective information. As summarized in Table 1 , these studies were scrutinized by devoting attention to the characterizations of two key processes constitutive of IEs: (i) receiving and acquiring, and (ii) interpreting information, either sensory or cognitive-affective. Overall, the findings suggest that IE studies conducted so far have drawn a more nuanced pictured of the ways in which people experience sensory information. This is due to empirical studies examining how people receive or acquire perceptual information in diverse contexts such as health, grocery 
shopping and social dancing. In comparison, the picture of experiencing cognitiveaffective information has remained more rudimentary, even though there are a few investigations illustrating how such information is received or acquired in health-related contexts such as renal self-care and imminent natural disaster. Moreover, there are investigations describing how people experience affective information in hobby-related situations characterized by the phenomena of flow. Overall, the answers to research questions 1 and 2 suggest that the studies conducted so far have created a preliminary though largely descriptive picture of IEs.

Research question 3 focused on the strengths and weaknesses of the characterizations of IE. As Table 1 indicates, the main strength of IE studies can be found in the illuminative descriptions of how people receive or acquire sensory and cognitive-affective information. However, the weaknesses overweigh the strengths. This is mainly due to that IE studies have seldom reflected the nature of human experience in the context of informational phenomena (for positive exceptions, see Gorichanaz, 2017b; Lloyd, 2014). Approaching experience as a self-explanatory construct means that the specific nature of IE remains unclear. Open questions include, for example, should all cases - even trivial ones - in which a person deals or engages with information be qualified as information "experiences"? If yes, this may reduce the discriminatory power of the concept of IE.

To avoid this problem, the concept of experience may be defined more strictly so that only noticeable events in which a person deals with information are qualified as IEs. This approach would be better in accord with the idea of experience as Erlebnis if we follow the characterization offered by von Glasersfeld and Ackermann (2011: 194): “a person's experience as lived through: the undergoing of some noticeable event, as apprehended through the senses or mind, affecting him or her here and now". On the other hand, drawing on the ideas of the first-person approach, the boundary line between trivial and noticeable events may be flexible and it can best be defined by the person herself in a specific situation. Unexpectedly hearing a cancer diagnosis exemplifies a shocking IE for most people, while encountering painful sensations during a routine self-care procedure may be a noticeable though not particularly dramatic event for a renal patient. On the other hand, it is less evident whether absent-mindedly browsing Facebook would represent a noticeable event giving rise to a memorable IE.

Another weakness of IE studies is that the characterizations of how people interpret sensory and cognitive-affective information have remained at a descriptive level. This problem is particularly evident in studies characterizing the interpretation of cognitive-affective information. This weakness is probably due to that the study participants have found it difficult to explain how they reflected cognitive-affective information recalled from memory. Moreover, interpretation processes of this kind may partly occur at a subconscious level so that they cannot be fully articulated. This methodological issue is highly pertinent because researchers are debating about the extent to which it is possible to empirically capture people's experiences of reality and the ways in which they have interpreted such experiences in past situations (Haye and Larrain, 2013; Potter, 2012). Simply asking interviewees to recall such events may not be sufficient. Aternative methods of data gathering such as talking aloud may enable a more nuanced picture of the 
interpretation of information received or acquired during an event. On the other hand, selfobservation and reporting of an ongoing IE may reduce its authenticity.

The above weaknesses are indicative of the needs to for further IE research, both conceptual and empirical. One of the gaps to be bridged in future studies deal with the ways in which people interpret information as an integral part of IE. To achieve this, there is a need to make use of established theoretical models such as Interacting Cognitive Subsystems (ICS) (Barnard et al., 2007). This model departs from the assumption that human mind has multiple modes that are responsible for receiving and processing new information cognitively and emotionally. Drawing on cognitive-behavioural ideas, the model specifies nine interactive cognitive subsystems which are specialised to process information in a particular type of representation constructed in a mental "code". Visual, Acoustic, and Body State subsystems process sensory codes; their characteristics are determined by constraints on sense receptors such as warmth and pain. Two other subsystems are specialised to control outputs to skeletal and vocal musculatures. The four remaining "central subsystems" are specialised to process more abstract mental codes. Two of these subsystems represent structures in the auditory verbal (Morphonolexical) domain. The remaining subsystems process two qualitatively different ways of encoding meaning, i.e., "Propositional" and "Implicational" meaning. The former kind of meaning is that most usually thought of as the kind of meanings that are expressed in sentences while implicational meaning encodes more holistic and abstract schematic models of cognitiveaffective experience. Even though generic models such as ICS are fairly complex, they hold potential for elaborating the picture of how sensory and cognitive-affective information is processed and interpreted within the human mind.

Another significant topic of further research deals with the relationships between experiencing sensory and cognitive-affective information. As the above types of IE tend to be interwoven, the examination of this topic would serve the ends of creating a more holistic picture of IEs. Thus far, the most relevant investigations conceptualizing the interplay of the above types of IE describe how people experience both sensory and cognitive-affective information. For example, Lupton's (2014) empirical investigation of IEs among those who compose music for an audience and those who dance socially with a partner revealed that music and dance are art forms that involve a full mind-body experience, integrating the kinaesthetic, visual, cognitive and affective domains, as well as documentary forms of information. In this context, IE incorporates both tangible (physical) and intangible (cognitive-affective) forms of information.

Typical to IE studies, however, Lupton's analysis of the interplay of the sensory and cognitive-affective aspects of IE remained at a general level, thus revealing the need for further research. The above investigation was also typical in that the main attention was directed to how the participants reported their ways to access and use information sources of diverse kind, rather than how they subjectively reflected situations in which sensory information was related to other forms of information. Finally, as IEs are often based on the acquisition and interpretation of visual information, one of the pertinent topics of further research is how such IEs are related to experiencing cognitive-affective information. A classic example of situations giving rise to such IEs is reading books for 
pleasure (Ross, 1989). Currently, a growing part of IEs occur in social media when people read and browse online content (Qauyym and Williamson, 2014). This is a significant topic for further research because it would specify the picture of IEs based on interplay of acquiring and interpreting visual, auditory and cognitive-affective information.

\section{Conclusion}

The present study elaborated the picture of IE by approaching it as a process lived through, constituted by the reception, acquisition and interpretation of sensory and cognitiveaffective information. The findings highlight the fact that so far, the construct of IE has remained quite vague. This is mainly due to that the nature of experience - the fundamental constituent of IE - has not been reflected in greater depth in the context of informational phenomena such as information seeking and information use. Another major gap in IE research is the insufficient analysis of the ways in which sensory and cognitive-affective information are interpreted.

As the present study focused on a limited number of studies characterizing how people experience sensory and cognitive-affective information, the findings do not cover the whole domain of IE research. For example, specific phenomena such as document experience and museum experience (Gorichanaz and Latham, 2016; Latham, 2014; Latham, 2018) were not examined. Nevertheless, it is evident that IE studies hold potential for substantiating and deepening the findings of information behaviour research from the first-person perspective, particularly in issues dealing with seeking and using sensory and affective information. This contribution is welcome because traditionally, information behaviour research has concentrated on the ways in which people seek and use cognitive information, while other types of information have remained in the shadow of the above approach (Fisher and Landry, 2007: 211).

The potential of IE research can be strengthened further by scrutinizing the interplay of experiencing sensory and cognitive-affective information. To this end, investigations examining how people receive and interpret corporeal (embodied) information in relation to cognitive-affective information in everyday contexts such as health self-care and grocery shopping are particularly relevant for information scientists. This is because these topics can be explored by making use of the ideas developed in the fields of medical science and consumer research. The interplay of sensory and cognitive-affective information can also be examined in the context of document and museum experience. Latham $(2015 ; 2018)$ has pioneered in this field by exploring how a person experiences museum objects in four fundamental ways: through herself (the aspect of Self), through others (Relation), through the physical thing itself (Presence), and through the context (Surround). For example, analysing how people experience museum objects would elaborate the picture of IE by demonstrating how visual and aural information received from such objects during a guided tour is interpreted, combined with the visitor's prior knowledge of the museum objects. Investigations on this topic are also relevant because they would elaborate the picture of IE as a context-specific phenomenon. For example, a museum object may be experienced differently when the same museum is revisited. It is evident that studies such 
as these would contribute to a more holistic picture of the ways in which people deal with information as an integral part of human existence.

Declaration of Conflicting Interests

The author declared no potential conflicts of interest with respect to the research, authorship, and/or publication of this article.

Funding

The author received no financial support for the research, authorship, and/or publication of this article.

\section{References}

Afzal, W (2018) Weaving an affective framework for information behaviour research: a consideration of 'trilogy of mind' and 'flow'. Information Research 23 (4). Available at: http://www.informationr.net/ir/23-4/isic2018/isic1816.html

Barnard, PJ, Duke, DJ, Byrne, RW and Davidson, I (2007) Differentiation in cognitive and emotional meanings: an evolutionary analysis. Cognition and Emotion 21 (6): 1155-1183.

Bates, MJ (2017) Information. In: McDonald, JD and Levine-Clark, M (eds) Encyclopedia of Library and Information Sciences. 4th. ed. London: Taylor \& Francis, pp. 2048-2063.

Bates, MJ (2018) Concepts for the study of information embodiment. Library Trends 66 (3): 239-266.

Bruce, C (1994) Research students' early experiences of the dissertation literature review. Studies in Higher Education 19 (2): 217-229.

Bruce, C (1997) The Seven Faces of Information Literacy. Adelaide, Australia: Auslib Press.

Bruce, C, Davis, K, Hughes, H, Partridge, H and Stoodley, I (2014a) Afterword. In: Bruce, $\mathrm{C}$ et al. (eds) Information Experience: Approaches to Theory and Practice. Bingley, UK: Emerald, pp. 315-320.

Bruce, C, Davis, K, Hughes, H, Partridge, H and Stoodley, I (2014b) Information experience: contemporary perspectives. In: Bruce, $\mathrm{C}$ et al. (eds) Information Experience: Approaches to Theory and Practice. Bingley, UK: Emerald, pp. 3-15.

Buckland, MK (1991) Information and Information Systems. New York, NY: Greenwood Press. 
Burmester, M, Mangold, M and Tille, R (2013) Information experience: Informationen zum Erlebnis machen. Information Wissenschaft \& Praxis 64 (5): 252-259.

Case, DO and Given, LM (2016) Looking for Information. A Survey of Research on Information Seeking, Needs and Behavior. 4th ed. Bingley, UK: Emerald.

Clark, S (2014) Exploring the lived information seeking experiences of mature students. Journal of Information Literacy 8 (1): 58-84. Available at: http://ojs.lboro.ac.uk/ojs/index.php/JIL/article/view/LLC-V8-I1-2014/1953

Cox, A (2018) Embodied knowledge and sensory information: theoretical roots and inspirations. Library Trends 66 (3): 223-238.

Cox, A, Griffin, B and Hartel, J (2018) Introduction. Library Trends 66 (3): 219-222.

Csikszentmihalyi, M (1990) Flow: The Psychology of Optimal Experience. New York: Harper and Row.

Davidson, RJ, Scherer, KR and Goldsmith, HH (2003) Introduction. In: Davidson, RJ et al. (eds), Handbook of Affective Sciences. Oxford: Oxford University Press, pp. xii - xvii.

Demasson, A, Partridge, H, and Bruce, C (2016) Information literacy and the serious leisure participant: variation in the experience of using information to learn. Information Research 21 (2). Available at: http://InformationR.net/ir/21-2/paper711.html

Dewey, J (1929) Experience and Nature. $2^{\text {nd }}$ ed. Chicago: Open Court.

Emanuel, AS, Godinho, CA, Steinman, C and Updegraff, JA (2018) Education differences in cancer fatalism: the role of information-seeking experiences. Journal of Health Psychology 23 (12): 1533-1544.

Fisher, KE and Landry, CF (2007) Understanding the information behaviour of stay-athome mothers through affect. In Nahl, D and Bilal, D (eds.), Information and Emotion. The Emergent Affective Paradigm in Information Behavior Research and Theory. Medford, NJ: Information Today, Inc., pp. 211-233.

Fox, K (2008) Rethinking experience: what do we mean by this word "experience"? Journal of Experiential Education 31 (1): 36-54.

Fulton, C (2009) The pleasure principle: the power of positive affect in information seeking. Aslib Proceedings: New Information Perspectives 61 (3): 245-261.

Furner, J (2004) Conceptual analysis: a method for understanding information as evidence, and evidence as information. Archival Science 4 (3-4): 233-265 
Geertz, C (1986) Making experiences, authoring selves. In: Bruner, EM and Turner, V (eds), The Anthropology of Experience. Chicago: University of Illinois Press, pp. 373-380.

Godbold, N (2014) Experiential brutality in sense making: researching dynamic sense making processes in online discussions about kidney failure. In: Bruce, $\mathrm{C}$ et al. (eds) Information Experience: Approaches to Theory and Practice. Bingley, UK: Emerald, pp. 151-167.

von Glasersfeld, E and Ackermann, EK (2011) Reflections on the concept of experience and the role of consciousness. Unfinished fragments, with comments by Vincent Kenny and George Forman. Constructivist Foundations 6 (2): 193-203.

Gorichanaz, T (2017a) Auto-hermeneutics: a phenomenological approach to information experience. Library and Information Science Research 39 (1): 1-7.

Gorichanaz, T (2017b) Information and experience, a dialogue. Journal of Documentation 73 (3): 500-508.

Gorichanaz, T (2017c) There's no shortcut: Building understanding from information in ultrarunning. Journal of Information Science 43 (5): 713-722.

Gorichanaz, T (2019) A first-person theory of documentation. Journal of Documentation 75 (1): 190-212.

Gorichanaz, T and Latham, KF (2016) Document phenomenology: a framework for holistic analysis. Journal of Documentation 72 (6): 1114-1133.

Harlan, AM (2014) Information experiences of teen content creators. In: Bruce, C et al. (eds) Information Experience: Approaches to Theory and Practice. Bingley, UK: Emerald, pp. 101-115.

Haye, A, and Larrain, A (2013) Discursively constituted experience, or experience as reply: a rejoinder. Theory and Psychology 23 (1): 131-139.

Heinström, J (2014) The emotional valence of information experience: relation to personality and approach to studying. In: Bruce, $\mathrm{C}$ et al. (eds) Information Experience: Approaches to Theory and Practice. Bingley, UK: Emerald, pp. 275-293.

Lambert, SD, Loiselle, CG and Macdonald, E (2009) An in-depth exploration of information-seeking behaviour among individuals with cancer. Part 2: understanding differential patterns of information disinterest and avoidance. Cancer Nursing 32 (1): 2636.

Laplante, A, and Downie, JS (2011) The utilitarian and hedonic outcomes of music information-seeking in everyday life. Library and Information Science Research 33(3): 202-210. 
Lash, S (2006) Experience. Theory, Culture and Society 23 (2-3): 335-341.

Latham, KF (2014) Experiencing documents. Journal of Documentation 70 (4): 544-561.

Latham, KF (2015) What is "the real thing" in the museum? An interpretative phenomenological study. Museum Management and Curatorship, 30 (1): 2-20.

Latham, KF (2018) The wonders of the Augsburg Cabinet: three ways of experiencing a document. Proceedings from the Document Academy 5(2). Available at: https://ideaexchange.uakron.edu/docam/vol5/iss2/10

Lazarus, RS (1999) The cognition-emotion debate: a bit of history. In Dalgleish, T and Power, MJ (eds), Handbook of Cognition and Emotion. Chichester, UK: John Wiley, pp. 3-19.

Lloyd, A (2009) Informing practice: information experiences of ambulance officers in training and on-road practice. Journal of Documentation 65 (3): 396-419.

Lloyd, A (2014) Informed bodies: does the corporeal experience matter to information literacy? In: Bruce, $\mathrm{C}$ et al. (eds) Information Experience: Approaches to Theory and Practice. Bingley, UK: Emerald, pp. 85-99.

Lueg, CP (2014) Characteristics of human perception and their relevance when studying information behaviour. Journal of Documentation 70 (4): 562-574.

Lupton, M (2014) Creating and expressing: information-as-it-is-experience. In: Bruce, C et al. (eds) Information Experience: Approaches to Theory and Practice. Bingley, UK: Emerald, pp. 69-84.

McCarthy, J and Wright, P (2004) Technology as Experience. Cambridge, Mass: The MIT Press.

Merriam-Webster (2019) Experience. Available at: https://www.merriamwebster.com/dictionary/experience

Mitchell, ET (2013) The theatre of information engagement: designing immersive information experiences in libraries. Journal of Web Librarianship 7 (3); 343-348.

Mosunova, LA (2017) Theoretical approaches to defining the concept of the "perception of the meaning of information". Scientific and Technical Information Processing 44 (3): 175-183.

Niedenthal, PM (1990) Implicit perception of affective information. Journal of Experimental Social Psychology 26 (6): 505-527. 
Ocepek, MG (2018) Sensible shopping: a sensory exploration of the information environment of the grocery store. Library Trends 66 (3): 371-394.

Petri, HL and Govern, JM (2004) Motivation: Theory, Research and Applications. $5^{\text {th }}$ ed. Belmont, CA: Wadsworth.

Pessoa, L (2008) On the relationship between emotion and cognition._Nature Reviews Neuroscience 9 (2): 148-158.

Potter, J (2012) How to study experience. Discourse and Society 23 (5): 576-588.

Qayyum, MA and Williamson, K (2014) The online information experiences of newsseeking young adults. Information Research 19 (2). Available at: http://InformationR.net/ir/19-2/paper615.html

Roederer, C (2012) A contribution to conceptualizing the consumption experience: emergence of the dimensions of an experience through life narratives. Recherche et Applications en Marketing 27 (3): 81-95.

Ross, CS ((1999) Finding without seeking: the information encounter in the context of reading for pleasure. Information Processing and Management 35 (6): 783-799.

Roth, W-M and Jornet, A (2014) Toward a theory of experience. Science Education 98 (1): 106-126.

Smith, DW (2013) Phenomenology. In: Stanford Encyclopedia of Philosophy. Available at: https://plato.stanford.edu/entries/phenomenology/

Sternberg, RJ (2009) Cognitive Psychology. $5^{\text {th }}$ ed. Belmont, CA: Wadsworth.

Throop, CJ (2003) Articulating experience. Anthropological Theory 3 (2): 219-241.

Yates, C and Partridge, H (2014) Exploring information literacy during a natural disaster: the 2011 Brisbane flood. In: Bruce, $\mathrm{C}$ et al. (eds) Information Experience: Approaches to Theory and Practice. Bingley, UK: Emerald, pp. 119-134.

Yates, C, Partridge, H, and Bruce, C (2012) Exploring information experience through phenomenography. Library and Information Research 36 (112): 96-119.

\section{Author biography}

Reijo Savolainen is professor emeritus at the Faculty of Information Technology and Communication Sciences, Tampere University, Finland. His research interest areas include information needs, seeking and use. From the 1990s, his major area of research has been everyday life information seeking (ELIS). Currently, he is elaborating on the conceptual and empirical issues of everyday life information practices. His publications include about 
180 articles and books published in national and international forums such as Information Processing \& Management; Journal of the American Society for Information Science and Technology; Journal of Documentation; Library \& Information Science Research, and Library Quarterly. His newest book is Everyday Information Practices. A Social Phenomenological Practice (Lanham, MD: The Scarecrow Press, 2008.

\section{Appendix 1. Items included in the sample of 43 IE studies}

1. Beretta, P, Sayyad Abdi, E and Bruce, C (2018) Immigrants' information experiences: an informed social inclusion framework. Journal of the Australian Library and Information Association 67 (4): 373:393.

2. Bruce, C (1994) Research students' early experiences of the dissertation literature review. Studies in Higher Education 19 (2): 217-229.

3. Bruce, C (1997) The Seven Faces of Information Literacy. Adelaide, Australia: Auslib Press.

4. Bruce, C, Davis, K, Hughes, H, Partridge, H and Stoodley, I (2014a) Afterword. In: Bruce, $\mathrm{C}$ et al. (eds) Information Experience: Approaches to Theory and Practice. Bingley, UK: Emerald, pp. 315-320.

5. Bruce, C, Davis, K, Hughes, H, Partridge, H and Stoodley, I (2014b) Information experience: contemporary perspectives. In: Bruce, $\mathrm{C}$ et al. (eds) Information Experience: Approaches to Theory and Practice. Bingley, UK: Emerald, pp. 3-15.

6. Bruce, C and Partridge, HL (2011) Identifying and delineating information experience as a research domain: a discussion paper. In: Social Media and Information Practices Workshop, 10-11 November,2011, Borås, Sweden. Brisbane: Queensland University of Technology. Available at: https://eprints.qut.edu.au/47204/2/bruce_partridge.pdf

7. Clark, S (2014) Exploring the lived information seeking experiences of mature students. Journal of Information Literacy 8 (1): 58-84.

8. Demasson, A, Partridge, H, and Bruce, C (2016) Information literacy and the serious leisure participant: variation in the experience of using information to learn. Information Research 21 (2). Available at: http://InformationR.net/ir/212/paper711.html

9. Emanuel, AS, Godinho, CA, Steinman, C and Updegraff, JA (2018) Education differences in cancer fatalism: the role of information-seeking experiences. Journal of Health Psychology 23 (12): 1533-1544.

10. Godbold, N (2014) Experiential brutality in sense making: researching dynamic sense making processes in online discussions about kidney failure. In: Bruce, $\mathrm{C}$ et al. (eds) Information Experience: Approaches to Theory and Practice. Bingley, UK: Emerald, pp. 151-167.

11. Gorichanaz, T (2017a) Auto-hermeneutics: a phenomenological approach to information experience. Library and Information Science Research 39 (1): 1-7.

12. Gorichanaz, T (2017b) Information and experience, a dialogue. Journal of Documentation 73 (3): 500-508. 
13. Gorichanaz, T (2017c) There's no shortcut: Building understanding from information in ultrarunning. Journal of Information Science 43 (5): 713-722.

14. Gorichanaz, T (2019) A first-person theory of documentation. Journal of Documentation 75 (1): 190-212.

15. Gross, M and Latham, D (2011) Experiences with and perceptions of information: a phenomenographic study of first-year college students. Library Quarterly 81 (2): 161-186.

16. Harlan, AM (2014) Information experiences of teen content creators. In: Bruce, C et al. (eds) Information Experience: Approaches to Theory and Practice. Bingley, UK: Emerald, pp. 101-115.

17. Heinström, J (2014) The emotional valence of information experience: relation to personality and approach to studying. In: Bruce, $\mathrm{C}$ et al. (eds) Information Experience: Approaches to Theory and Practice. Bingley, UK: Emerald, pp. 275293.

18. Hepworth, M, Almemahdi, F and Maynard, S (2014) A reflection on the relationship between the study of people's information behaviour and information literacy: changes in epistemology and focus. In: Bruce et al. (eds) Information Experience: Approaches to Theory and Practice. Bingley, UK: Emerald, pp. 5165.

19. Hughes, H (2006) Responses and influences: a model of online information use for learning. Information Research 12(1). Available at: http://www.informationr.net/ir/12-1/paper279.html

20. Hughes, H (2014) Researching information experience: methodological snapshots. In: Bruce et al. (eds) Information Experience: Approaches to Theory and Practice. Bingley, UK: Emerald, pp. 33-50.

21. Ivarsson, B, Ekmehag, B and Sjöberg, T (2013) Patients' experiences of information and support during the first six months after heart or lung transplantation. European Journal of Cardiovascular Nursing 12 (4): 400-406.

22. Jenkins, J (2014) How to lose friends and alienate people: the high cost to business of poor information experiences. In: Bruce et al. (eds) Information Experience: Approaches to Theory and Practice. Bingley, UK: Emerald, pp. 189-202.

23. Johnston, N, Partridge, H and Hughes, H (2014) Understanding the information literacy experiences of EFL (English as a foreign language) students. Reference Services Review 42 (4): 552-568.

24. Latham, KF (2014) Experiencing documents. Journal of Documentation 70 (4): 544-561.

25. Lloyd A (2006) Information literacy landscapes: An emerging picture. Journal of Documentation 62(2): 570-583.

26. Lloyd, A (2009) Informing practice: information experiences of ambulance officers in training and on-road practice. Journal of Documentation 65 (3): 396-419.

27. Lloyd, A (2014) Informed bodies: does the corporeal experience matter to information literacy? In: Bruce, $\mathrm{C}$ et al. (eds) Information Experience: Approaches to Theory and Practice. Bingley, UK: Emerald, pp. 85-99. 
28. Lloyd, A and Wilkinson, J (2019). Tapping into the information landscape: refugee youth enactment of information literacy in everyday spaces. Journal of Librarianship and Information Science 51 (1): 252-259.

29. Lupton, M (2014) Creating and expressing: information-as-it-is-experience. In: Bruce, $\mathrm{C}$ et al. (eds) Information Experience: Approaches to Theory and Practice. Bingley, UK: Emerald, pp. 69-84.

30. Maybee, C (2014). Experiences of informed learning in the undergraduate classroom. In: Information experience: approaches to theory and practice. Bingley, UK: Emerald, pp. 259-273.

31. Maybee, C, Bruce, C, \& Lupton, M and Rebmann, K (2017) Designing rich information experiences to shape learning outcomes. Studies in Higher Education 42 (12): 2373-2388.

32. Ocepek, MG (2018) Sensible shopping: a sensory exploration of the information environment of the grocery store. Library Trends 66 (3): 371-394.

33. Partridge, H, McAllister, L, Toohey, L, Field, R, Crowe, J and Allcock, A (2018) Understanding the information experiences of parents involved in negotiating postseparation parenting arrangements. Journal of Librarianhip and Information Science (forthcoming, published online July 18, 2018, https://doiorg.libproxy.tuni.fi/10.1177/0961000618787604)

34. Partridge, H and Yates, C (2014) Researching information experience: object and domain. In: Bruce, $\mathrm{C}$ et al. (eds) Information Experience: Approaches to Theory and Practice. Bingley, UK: Emerald, pp. 19-32.

35. Qayyum, MA and Williamson, K (2014) The online information experiences of news-seeking young adults. Information Research 19 (2). Available at: http://InformationR.net/ir/19-2/paper615.html

36. Reddy, V (2014). Information experience in the context of information seeking methods by prospective students. In: Bruce, $\mathrm{C}$ et al. (eds) Information Experience: Approaches to Theory and Practice. Bingley, UK: Emerald, pp. 295-311.

37. Smeaton, K, Bruce, C, Hughes, H and Davis, K (2017) The online life of individuals experiencing socioeconomic disadvantage: how do they experience information? Information Research 22 (3). Available at: http://InformationR.net/ir/22-3/paper768.html

38. Smith, M and Hepworth, M (2012) Young people: a phenomenographical investigation into the ways they experience information. Libri 62 (2): 157-173.

39. Wathen, CN and Harris, RM (2006) An examination of the health information seeking experiences of women in rural Ontario, Canada. Information Research 11 (4). Available at: http://InformationR.net/ir/11-4/paper267.html

40. Yates, C and Partridge, H (2014) Exploring information literacy during a natural disaster: the 2011 Brisbane flood. In: Bruce, C et al. (eds) Information Experience: Approaches to Theory and Practice. Bingley, UK: Emerald, pp. 119-134.

41. Yates, C and Partridge, H (2015) Citizens and social media in times of natural disaster: exploring information experience. Information Research 20 (1). Available at: http://InformationR.net/ir/20-1/paper659.html 
42. Yates, C and Partridge, $\mathrm{H}$ and Bruce, C (2009) Learning wellness: how ageing Australians experience health information literacy. Australian Library Journal 58 (3): 269-285.

43. Yates, C, Partridge, H, and Bruce, C (2012) Exploring information experience through phenomenography. Library and Information Research 36 (112): 96-119. 